\title{
Effect of Educational Nursing Protocol on Minimizing Venous Thromboembolism for Patients Undergoing Simultaneously Arthroscopic ACLR and High Tibial Osteotomy
}

\author{
Amira Ahmed Hussein ${ }^{1}$, Zienab Abd El-lateef Mohammad ${ }^{2}$, Hesham Elkady ${ }^{3}$ \& Hala Mohamed Ghanem ${ }^{4}$. \\ 1. Clinical Demonstrator of Medical-Surgical Nursing, Faculty of Nursing, Assiut University, Egypt. \\ 2. Professor of Medical-Surgical Nursing, Faculty of Nursing, Assiut University, Egypt. \\ 3. Professor of Orthopedic Surgery, Faculty of Medicine, Assiut University, Egypt. \\ 4. Assistant Professor of Medical-Surgical Nursing, Faculty of Nursing, Assiut University, Egypt.
}

\begin{abstract}
Background: Venous thromboembolism (VTE) refers to a blood clot that starts in a vein. It includes both deep vein thrombosis and pulmonary embolism. Aim: Evaluate the effect of implementation of educational nursing protocol on minimizing VTE for patients undergoing simultaneously arthroscopic anterior cruciate ligament reconstruction (ACLR) and high tibial osteotomy (HTO). Research design: Quasi experimental (Pre/posttest) research design was utilized. Subjects: A convenient sample of 30 adult patients undergoing simultaneously arthroscopic ACLR and HTO (age: 18 to 50 years old) both sexes were recruited. Setting: The study was conducted in the Unit of Arthroscopy and Sports Injuries in Orthopedic Department and the Arthroscopic Outpatient Clinic at Assiut University Hospital. Tools: (I) Pre/post patient structured interview questionnaire and (II) VTE evaluation sheet. Result: there was statistical significant difference regarding total knowledge score for studied patients in pre and post implementing nursing protocol and no patients were developing VTE. Conclusion: the study findings revealed that educational nursing protocol were significally effective in improving patient's knowledge about VTE and in preventing VTE.
\end{abstract}

\section{Key words: Nursing Protocol, Venous Thromboembolism \& Anterior Cruciate Ligament Reconstruction, High Tibial Osteotomy.}

\section{Introduction}

High tibial osteotomy (HTO) is a widely accepted and performed procedure to treat medial knee osteoarthritis. In HTO the tibia is cut and then reshaped to relive pressure on the medial side of the knee joint (Seung et al., 2018). Anterior cruciate ligament reconstruction (ACLR) is a routine surgical procedure to restore knee stability in active patients after acute Anterior Cruciate Ligament (ACL) injuries or in patients with chronic anterior knee instability (Calloway et al., 2018). Simultaneously arthroscopic ACLR and HTO surgeries are required if patients have symptomatic arthritis in the medial part of the knee as well as instability of ACL. This surgery is a "joint salvage" procedure with a view to achieve a more stable and pain improved knee, with a view to delay or avoid knee replacement (Jin et al., 2018).

Venous thromboembolism (VTE) refers to a blood clot that starts in a vein. It includes both deep vein thrombosis (DVT) and pulmonary embolism (PE). The incidence of VTE after knee arthroscopy without prophylaxis is reported to be as low as $0.4 \%$, when diagnosed clinically, to as high as $17.9 \%$ when diagnosed by screening asymptomatic patients (Janssen et al., 2016). In DVT one or more blood clots forms in vein that is deep inside the body, it mainly affects the large veins in the lower limb. The clot(s) can cause partial or complete blocking of circulation in the vein. The DVT is often asymptomatic but also may be associated with pain, swelling, tenderness, discoloration, redness or warmth of the affected area (Olaf, \& Cooney, 2017).

PE occurs when a DVT clot breaks and travels in the blood stream, first to the heart and then to the lungs, where it can partially or completely block a pulmonary artery or one of its branches. PE is a serious, life threatening complication with signs and symptoms that include: shortness of breath, rapid heartbeat, sweating, and sharp chest pain especially during deep breathing (Nadim et al., 2018).

There are numerous measures that nursing staff can utilize to prevent VTE in high risk group includes: mechanical methods such as programmed ambulation, leg exercises, deep breathing exercise, application of compression stocking or intermittent calf muscle compression, hydration maintenance. Pharmacologic methods which include use of anticoagulant medication such as (heparin, warfarin and aspirin) (Zhu et al., 2018).

The main goal of nursing protocol is to reduce VTE mortality and morbidity associated with surgical procedure and hospitalization. Early and frequent ambulation, Leg and deep breathing exercises can improve circulation and help in preventing VTE, compression stocking helps decrease venous pressure, 


\section{Significance of the study}

patients with simultaneously arthroscopic ACLR and HTO are at risk for developing VTE and/or other complications such as post thrombotic syndrome (PTS) and chronic thromboembolic pulmonary hypertension (CTEPH) due to prolonged operative time and delay in full ambulation after surgery, which then lead to prolonged hospitalization, increased costs and higher mortality rates. The incidence of DVT after arthroscopic knee surgery in Egypt was 2\%. According to the patients records in Arthroscopy and sports injury unit through 2017 2018 , it found that there were about $7,46 \%$ of patients performed simultaneously arthroscopic ACLR and HTO surgery per year, Hence, patients are in need for educational nursing protocol.

\section{Aim of the study}

The aims of this study were:-

1. Assess patient's knowledge about VTE and its prevention.

2. Design and implement educational nursing protocol for patients undergoing simultaneously arthroscopic ACLR and HTO.

3. Evaluate the effect of educational nursing protocol on minimizing venous thromboembolism for patients undergoing arthroscopic simultaneously ACLR and HTO.

\section{Hypothesis}

To fulfill the aim of the study, the following hypothesis was formulated.

1. The knowledge of the studied patients after application of educational nursing protocol will be higher than their knowledge before application of protocol.

2. The occurrence of VTE in the studied patients will be reduced after application of educational nursing protocol.

\section{Operational definitions}

Nursing protocol: A specific written procedure that prescribes nursing actions in a given situation.

Venous Thromboembolism (VTE): Venous thromboembolism (VTE) refers to a blood clot that starts in a vein. It includes both deep vein thrombosis and pulmonary embolism

Patient undergoing: pre, intra and post.

Patients and methods

Research design:

Quasi experimental (Pre/posttest) research design was utilized in this study.

\section{Setting}

The study was conducted in the Unit of Arthroscopy and Sports Injuries in Orthopedic Department and the Arthroscopic Outpatient Clinic at Assiut University Hospital.

\section{Sample}

The study included a convenient sample of (30) adult patients (males and females) who undergoing simultaneously arthroscopic ACLR and HTO from the time of admission in the department (preoperatively), through a follow up period (three visits) through two months (first day, two weeks and two months postoperatively; which is the time of full ambulation. Their ages ranged from 18 to 50 years old.

The sample was calculated by using the following equation according to Thompson, Steven k. (2012) with confidence level at $95 \%$ and the flow rate of patients 100 cases /year and sample was selected 30 cases.

Tools

The following tools were utilized for data collection: Tool I: Pre/ post patient structured interview questionnaire

This tool was designed and developed by the researcher after passing through an extensive and relevant national and international literature review (World journal of orthopedics, 2016) and (The American journal of sports medicine, 2015) and consulting expertise in this area. Pre/posttest questionnaire was used prior to implementation of nursing protocol (pretest) to measure the exact knowledge level of studied patients about VTE. The same tool was used after the implementation of nursing protocol (posttest) to evaluate the knowledge after implementation of nursing protocol. It consisted of three parts:

Part 1: Demographic data of the studied patients To assess the personal data for studied patients which including age, gender, marital status, level of education, occupation.

Part 2: Medical data: This part was included present history, past history and hospital stay.

Part 3: Patient's knowledge about venous thromboembolism: It included definition, types, causes, risk factors, signs \& symptoms, complication and preventive measures.

\section{Scoring system}

The total number of questions was (39). It was used before the implementation of the nursing protocol to measure the exact knowledge level of patients about venous thromboembolism. The same tool was used after implementation of nursing protocol to evaluate the gain in knowledge after protocol. Some items was categorized and scored into either correct (1) score or incorrect (0) score and other item was categorized and scored into complete correct (2) score, incomplete correct (1) score, incorrect (0) score. The total score for all items was (50) score. Those who obtained $<70 \%$ were considered having unsatisfactory level $>70 \%$ were considered having satisfactory level. 
Tool II: Venous Thromboembolism evaluation sheet for patients

This tool was designed by the researcher based on extensive literature review (International journal of Nursing Didactics, 2019) and (Journal of Pharmacy and Pharmacology, 2019) to assess the development of VTE. It included four parts.

Part 1: Venous thromboembolism manifestation: This part was used to assess VTE manifestations and consisted of the following:

- The DVT manifestations as calf pain, calf tenderness, swelling, discoloration, warmth of the affected area and distention of superficial vein.

- The PE manifestations as shortness of breath, rapid heartbeat, and sharp chest pain especially during deep breathing.

Part 2: Homan's sign test: Wheeler 1985 developed Homan's sign test which also called dorsiflexion sign test (It is a physical examination procedure used to test for DVT. To assess Homan's sign, the patient's knee is in an extended position and the examiner forcefully dorsiflexes the patient's ankle. A positive sign is indicated when pain in the popliteal region and the calf is elicited as the foot is dorsiflexed).

Part 3: Laboratory test findings: (prothrombin time, prothrombin concentration and international normalised ratio (INR)).

Part 4: Doppler findings: This part will be done to assess the blood supply in the veins in the lower limbs. Normal results indicate that the images show no issues such as blockages of blood vessels. If the technician has found an irregularity, it could indicate a blood clot.

Educational nursing protocol for patients undergoing simultaneously arthroscopic ACLR and HTO.

This tool developed by the researchers based on national and international literature review (journal of the International Union of Angiology, 2017), European Journal of Anaesthesiology, 2018) \& (The Journal of arthroplasty, 2017). It was written in Arabic using simple language with illustrations images concerning knowledge about:

- Simultaneously arthroscopic ACLR and HTO surgery.

- Definition, causes, risk factors, signs \& symptoms and complication of VTE

- preventive measure of VTE (smoking cessation, weight reduction, maintenance of normal blood pressure and blood glucose level, hydration maintenance, diet, use of antithrombotic drugs, application of compression stocking, early and programed ambulation, leg exercises and deep breathing exercise).

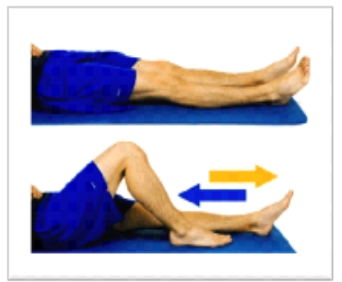

Fig (2): Heel slide exercise

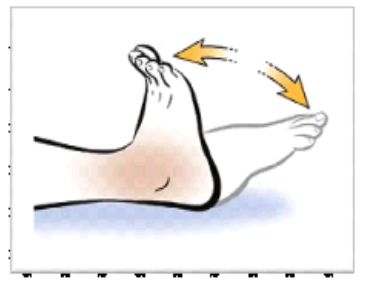

Fig (3): Ankle pump exercise
Adopted from. (Tova et al. 2016)

\section{Ethical consideration:}

Permission to carry out the study was obtained from the ethical committee of the Faculty of Nursing. An official letter was issued from the Dean of the Faculty of Nursing to the Head of the Orthopedic Department to collect the necessary data, and explain the aim and contents of the study to nursing supervisors and surgeons to gain their cooperation. Oral consent was obtained from patients or families that were willing to participate in the study after explanation of the nature and purposes of the study. Confidentiality and privacy was assured. Patients had the right to refuse to participate and or withdraw from the study without any rational at any time.

\section{Procedure}

The study was carried out on 3 phases

Phase one (preparatory phase)

Preparation of the data collection tools was carried out by the researchers after extensive national and international literature review (nursing and medical textbooks, journals and internet resources) at this phase.

\section{Content validity and reliability}

Validity of all tools was revised and checked by five academic experts (2 staff of orthopedic surgery and 3 staff of medical surgical nursing departments in Assuit University) who reviewed the tools for clarity, relevance, comprehensiveness, understanding and applicability. Minor modifications were required and correction was carried out accordingly.

Pilot study

A pilot study was conducted on $10 \%$ of patients (3 patients) to check the clarity, applicability, relevance and feasibility of the study tools, to identify the difficulties that may be faced during the application, and to estimate the time needed to fill them in. Necessary modifications were done and those patients were not included in the main study.

Phase two (Implementation phase)

An official permission to proceed with the proposed study was obtained from the head of orthopedic surgery department at Assiut University Hospital as well as hospital nursing director.

Once permission was granted to proceed with the proposed study, the investigators initiated data collection. 
Data were collected from arthroscopy and sports injury unit at assuit university hospital during the period from January/2019 to June/2019.

The tools filled through interviewing. This study was carried out at morning and afternoon shifts. The designed nursing protocol has been implemented for patients in two sessions.

\section{First session,}

- Started during 24 hours post admission in Arthroscopy and sports injury unit at Assuit university hospital.

- The studied patients were visited to initiate line of communication, explain nature and purpose of study to patients who agreed to participate in the study prior to any data collection.

- Each patient involved in the study was interviewed individually to fill out the first tool (pretest) to assess his/her knowledge about VTE (definition, causes, risk factors, sign \& symptoms, complication and preventive measures) then the researchers examined the patient for signs of VTE and perform Homan's sign test (pretest). These findings were the baseline for construction of the study intervention.

- The session took about 1 hour.

\section{Second session}

- During this session the researchers orient patient regarding the educational nursing protocol. The educational nursing protocol was included: Knowledge about the surgery (definition and preoperative preparations), knowledge about definition, causes, risk factors, signs \& symptoms and complication of venous thromboembolism, knowledge about preventive measure of venous thromboembolism (smoking cessation, weight reduction, maintenance of normal blood pressure and blood glucose level, hydration maintenance, diet, use of antithrombotic drugs, application of compression stocking devices, early programed ambulation, leg exercises and deep breathing exercise. we used pictures and brochure to enhance patient's understanding and helped them to retain the learned material.

- After completing the session there were about 1020 minutes for explaining and feedback. Reinforcement was performed according to patient's needs to ensure their understanding.

- Each patient obtained a hard copy of the booklet.

- The session took about 1 hour.

Phase three (Evaluation phase)

- Evaluation phase was carried out for all patients through filling (tool I and tool II).

- The patient's knowledge about VTE has been evaluated through filling (Tool I part 3) (posttest).
- VTE has been evaluated through (Tool II) at the first day postoperatively and after the patient's discharged from the hospital during follow up in the arthroscopy outpatient clinic (during his/her first visit after (two weeks postoperatively) then during his/her second visit (two months postoperatively) (posttest).

\section{Statistical analysis}

The collected data were coded then transformed into specially designed form so as to be suitable for entering into IBM compatible computer. All entered data were verified for any errors using Statistical Package for Social Sciences (SPSS) version 20 for windows. A descriptive statistics as number, percentage, mean and standard deviation. Data were collected, tabulated and statistically analyzed using Chi-square test, t-test, and ANOVA test.

\section{Limitations}

- This study was performed on small sample size in the selected sitting and depend on subjective data for detecting the incidence of DVT (VTE evaluation sheet) and not using objective data (diagnostic test for example Doppler) to confirm the occurrence of DVT because Doppler device was not available in orthopedic unit. 


\section{Results}

Table (1): Percentage distribution of demographic data for the studied patients $(n=30)$

\begin{tabular}{|c|c|c|}
\hline Variables $\quad$ (Years) & $\mathbf{N}=\mathbf{3 0}$ & $\%$ \\
\hline \multicolumn{3}{|l|}{ Age: } \\
\hline $18<30$ yrs & 6 & 20.0 \\
\hline $30<40 \mathrm{yrs}$ & 9 & 30.0 \\
\hline $40 \leq 50$ & 15 & 50.0 \\
\hline \multicolumn{3}{|l|}{ Sex: } \\
\hline Male & 25 & 83.3 \\
\hline Female & 5 & 16.7 \\
\hline \multicolumn{3}{|l|}{ Education level: } \\
\hline Illiterate & 3 & 10.0 \\
\hline Read and write & 4 & 13.3 \\
\hline Secondary school & 17 & 56.6 \\
\hline University & 6 & 20 \\
\hline \multicolumn{3}{|l|}{ Occupation: } \\
\hline Employed & 13 & 43.3 \\
\hline Manual work & 10 & 33.3 \\
\hline Not work & 7 & 23.3 \\
\hline \multicolumn{3}{|l|}{ Marital status: } \\
\hline Single & 5 & 16.7 \\
\hline Married & 25 & 83.3 \\
\hline
\end{tabular}

Table (2): Percentage distribution of medical data (present history) among the studied patients $(\mathrm{n}=30)$

\begin{tabular}{|c|c|c|}
\hline Variables (Minute) & $\mathbf{N}=\mathbf{3 0}$ & $\%$ \\
\hline \multicolumn{3}{|l|}{ Tourniquet time (Minute) } \\
\hline $60<90$ & - & \\
\hline $90<120$ & 29 & 96.7 \\
\hline$>120$ & 1 & 3.3 \\
\hline \multicolumn{3}{|l|}{ Duration of surgery(Minute) } \\
\hline $60<120$ & 29 & 96.7 \\
\hline $120<125$ & 1 & 3.3 \\
\hline \multicolumn{3}{|l|}{ Complication during surgery } \\
\hline Yes & 0.0 & 0.0 \\
\hline No & 30 & 100.0 \\
\hline \multicolumn{3}{|l|}{ Body Mass Index } \\
\hline Normal weight & 2 & 6.7 \\
\hline Over weight & 25 & 83.3 \\
\hline Obese & 3 & 10.0 \\
\hline
\end{tabular}

Table (3): Distribution of hospital stay among the studied patients $(n=30)$

\begin{tabular}{|l|l|}
\hline \multicolumn{2}{|c|}{ Hospital stay (days) } \\
\hline Mean \pm SD (Range) & $4.20 \pm .846(3-6)$ days \\
\hline
\end{tabular}


Table (4): Percentage distribution of medical data (past history) among the studied patients (n=30)

\begin{tabular}{|c|c|c|}
\hline Variables & $\mathbf{N}=\mathbf{3 0}$ & $\%$ \\
\hline \multicolumn{3}{|c|}{ Previous surgery. } \\
\hline Yes & 4 & 13.3 \\
\hline No & 26 & 86.7 \\
\hline \multicolumn{3}{|l|}{ Smoking. } \\
\hline Yes & 18 & 60.0 \\
\hline No & 12 & 40.0 \\
\hline \multicolumn{3}{|c|}{ Family history of VTE. } \\
\hline Yes & 2 & 6.7 \\
\hline No & 28 & 93.3 \\
\hline \multicolumn{3}{|c|}{ Personal history of VTE. } \\
\hline No & 30 & 100.0 \\
\hline \multicolumn{3}{|c|}{ History of varicose vein. } \\
\hline Yes & 2 & 6.7 \\
\hline No & 28 & 93.3 \\
\hline \multicolumn{3}{|c|}{ Duration of varicose vein } \\
\hline $1-3 \mathrm{yrs}$ & 1 & 3.3 \\
\hline $4-6 \mathrm{yrs}$ & 1 & 3.3 \\
\hline \multicolumn{3}{|c|}{ History of heart disease. } \\
\hline Yes & - & \\
\hline No & 30 & 100.0 \\
\hline \multicolumn{3}{|c|}{ History of diabetes mellitus. } \\
\hline Yes & 1 & 3.3 \\
\hline No & 29 & 96.7 \\
\hline \multicolumn{3}{|c|}{ Duration of diabetes mellitus. } \\
\hline $1-3 \mathrm{yrs}$ & - & \\
\hline $4-6 \mathrm{yrs}$ & 1 & 3.3 \\
\hline \multicolumn{3}{|c|}{ History of hypertension. } \\
\hline Yes & 5 & 16.7 \\
\hline No & 25 & 83.3 \\
\hline \multicolumn{3}{|c|}{ Duration of hypertension. } \\
\hline $1-3 \mathrm{yrs}$ & - & \\
\hline $4-6 \mathrm{yrs}$ & 5 & 16.7 \\
\hline \multicolumn{3}{|c|}{ Contraceptive pills for females. } \\
\hline Yes & 2 & 6.7 \\
\hline No & 2 & 6.7 \\
\hline \multicolumn{3}{|c|}{ Duration of Contraceptive pills. } \\
\hline $1-5 y r s$ & 1 & 3.3 \\
\hline $6-10 \mathrm{yrs}$ & 1 & 3.3 \\
\hline
\end{tabular}

Table (5): Comparison between Total levels of knowledge scores for the studied Patients in pre/post implementing nursing protocol $(n=30)$.

\begin{tabular}{|c|c|c|c|c|c|}
\hline $\begin{array}{c}\text { Total knowledge score } \\
\text { (total score 0-50 marks ) }\end{array}$ & Part I & $\mathbf{N}$ & Mean & $\begin{array}{c}\text { Std. } \\
\text { Deviation }\end{array}$ & Sign \\
\hline \multirow{2}{*}{$\begin{array}{l}\text { Patient knowledge about VTE } \\
\text { Total score } 0-12\end{array}$} & Preoperative & 30 & $.9333 \pm$ & 1.17248 & 0.001 \\
\hline & $1^{\text {st }}$ day post-operative & 30 & $11.5333 \pm$ & .57135 & \\
\hline \multirow{2}{*}{$\begin{array}{l}\text { Prevention of VTE before surgery } \\
0-17\end{array}$} & Preoperative & 30 & $1.0667 \pm$ & 1.11211 & 0.001 \\
\hline & $1^{\text {st }}$ day post-operative & 30 & $15.6667 \pm$ & 1.21296 & \\
\hline \multirow{2}{*}{$\begin{array}{l}\text { Prevention of VTE after } \\
\text { surgery(during hospitalization) } \\
0-14\end{array}$} & \begin{tabular}{|l|} 
Preoperative \\
\end{tabular} & 30 & $.7667 \pm$ & 1.52414 & \multirow{2}{*}{0.001} \\
\hline & $1^{\text {st }}$ day post-operative & 30 & $13.7000 \pm$ & .53498 & \\
\hline \multirow{2}{*}{$\begin{array}{l}\text { Prevention of VTE after discharge } \\
0-7\end{array}$} & Preoperative & 30 & $1.1000 \pm$ & .71197 & 0.001 \\
\hline & $1^{\text {st }}$ day post-operative & 30 & $6.2667 \pm$ & .78492 & \\
\hline \multirow{2}{*}{$\begin{array}{l}\text { Total knowledge } \\
0-50 \text { marks }\end{array}$} & Preoperative & 30 & $3.8667 \pm$ & 2.71310 & 0.001 \\
\hline & $1^{\text {st }}$ day post-operative & 30 & $47.1667 \pm$ & 2.11861 & \\
\hline Chi-square test & \multicolumn{3}{|c|}{$* *=$ high significance } & & \\
\hline
\end{tabular}


Table (6): Comparison between the studied patients regarding pulmonary embolism manifestation at different intervals $(\mathbf{n}=30)$.

\begin{tabular}{|c|c|c|c|c|c|c|c|c|c|}
\hline \multirow{2}{*}{\multicolumn{2}{|c|}{ Pulmonary embolism manifestation }} & \multirow{2}{*}{\multicolumn{2}{|c|}{ Pre-operative }} & \multirow{2}{*}{\multicolumn{2}{|c|}{$\begin{array}{c}\text { 1st day } \\
\text { Post-operative }\end{array}$}} & \multicolumn{2}{|c|}{$\begin{array}{c}2^{\text {nd }} \text { weeks } \\
\text { Post-operative }\end{array}$} & \multicolumn{2}{|c|}{$\begin{array}{c}2^{\text {nd }} \text { months } \\
\text { Post-operative }\end{array}$} \\
\hline & & & & & & & & & \\
\hline & & \multirow{2}{*}{$\begin{array}{l}\mathrm{N} \\
--\end{array}$} & \multirow{2}{*}{$\begin{array}{l}\% \\
-- \\
\end{array}$} & \multirow{2}{*}{$\mathrm{N}$} & \multirow{2}{*}{$\%$} & \multirow{2}{*}{ N } & \multirow{2}{*}{$\%$} & \multirow{2}{*}{$\begin{array}{l}\mathrm{N} \\
-\end{array}$} & \multirow{2}{*}{$\%$} \\
\hline Sharp chest pain. & Present & & & & & & & & \\
\hline & not present & 30 & 100.0 & 30 & 100.0 & 30 & 100.0 & 30 & 100.0 \\
\hline \multirow{2}{*}{$\begin{array}{l}\text { Shortness of } \\
\text { breath. }\end{array}$} & Present & -- & -- & & - & - & - & - & - \\
\hline & not present & 30 & 100.0 & 30 & 100.0 & 30 & 100.0 & 30 & 100.0 \\
\hline \multirow[t]{2}{*}{ Rapid heartbeat. } & Present & -- & -- & & - & - & - & - & - \\
\hline & not present & 30 & 100.0 & 30 & 100.0 & 30 & 100.0 & 30 & 100.0 \\
\hline
\end{tabular}

Chi-Square Tests $\quad * *=$ highly significance $* p \leq 0.01$

Table (7): Comparison between the studied patients regarding manifestations of deep vein thrombosis at different intervals $(\mathbf{n}=\mathbf{3 0})$.

\begin{tabular}{|c|c|c|c|c|c|c|c|c|c|c|}
\hline \multicolumn{2}{|c|}{ Deep vein thrombosis manifestation: } & \multicolumn{2}{|c|}{ Pre-operative } & \multicolumn{2}{|c|}{$\begin{array}{c}1^{\text {st }} \text { day } \\
\text { Post-operative }\end{array}$} & \multicolumn{2}{|c|}{$\begin{array}{c}\text { weeks } \\
\text { Post- } \\
\text { operative }\end{array}$} & \multicolumn{2}{|c|}{$\begin{array}{c}2 \text { months } \\
\text { Post- } \\
\text { operative }\end{array}$} & \multirow[t]{2}{*}{ P.V } \\
\hline & & $\mathbf{N}$ & $\%$ & $\mathbf{N}$ & $\%$ & $\mathbf{N}$ & $\%$ & $\mathbf{N}$ & $\%$ & \\
\hline \multirow[t]{2}{*}{ Calf muscle pain. } & Present & 4 & 13.3 & 4 & 13.3 & 2 & 6.7 & 0 & 0.0 & \\
\hline & not present & 26 & 86.7 & 26 & 86.7 & 28 & 93.3 & 30 & 100.0 & 0.013 \\
\hline \multirow[t]{2}{*}{ Calf muscle tenderness } & Present & 2 & 6.7 & 1 & 3.3 & 0.0 & 0.0 & 0.0 & 0.0 & \\
\hline & not present & 28 & 93.3 & 29 & 96.7 & 30 & 100.0 & 30 & 100.0 & 0.06 \\
\hline \multirow[t]{2}{*}{ Swelling of calf muscle. } & Present & 4 & 13.3 & 4 & 13.3 & 2 & 6.7 & 0 & 0.0 & \\
\hline & not present & 26 & 86.7 & 26 & 86.7 & 28 & 93.3 & 30 & 100.0 & 0.013 \\
\hline \multirow{2}{*}{$\begin{array}{l}\text { Skin Warmth of calf } \\
\text { muscle. }\end{array}$} & Present & 0.0 & 0.0 & 0.0 & 0.0 & 0.0 & 0.0 & 0.0 & 0.0 & \\
\hline & not present & 30 & 100.0 & 30 & 100.0 & 30 & 100.0 & 30 & 100.0 & $-\cdots$ \\
\hline \multirow{2}{*}{$\begin{array}{l}\text { Skin discoloration of } \\
\text { calf muscle }\end{array}$} & Present & 0.0 & 0.0 & 1 & 3.3 & 0.0 & 0.0 & 0.0 & 0.0 & \\
\hline & not present & 30 & 100.0 & 29 & 96.7 & 30 & 100.0 & 30 & 100.0 & 0.06 \\
\hline \multirow{2}{*}{$\begin{array}{l}\text { Distention of superficial } \\
\text { veins of calf muscle }\end{array}$} & Present & 0.0 & 0.0 & 0.0 & 0.0 & 0.0 & 0.0 & 0.0 & 0.0 & \\
\hline & not present & 30 & 100.0 & 30 & 100.0 & 30 & 100.0 & 30 & 100.0 & ---- \\
\hline
\end{tabular}

Table (8): Comparison between the studied patients regarding Homan`s sign test at different intervals $(\mathrm{n}=30)$.

\begin{tabular}{|c|c|c|c|c|c|c|c|c|}
\hline \multirow{2}{*}{$\begin{array}{c}\text { Homan`s sign test } \\
\end{array}$} & \multicolumn{2}{|c|}{ Pre-operative } & \multicolumn{2}{|c|}{$\begin{array}{c}\text { 1 day } \\
\text { Post-operative }\end{array}$} & \multicolumn{2}{c|}{$\begin{array}{c}\text { 2weeks } \\
\text { Post-operative }\end{array}$} & \multicolumn{2}{c|}{$\begin{array}{c}\text { 2 months } \\
\text { Post-operative }\end{array}$} \\
\cline { 2 - 9 } & $\mathbf{N}$ & $\mathbf{\%}$ & $\mathbf{N}$ & $\mathbf{\%}$ & $\mathbf{N}$ & $\mathbf{\%}$ & $\mathbf{N}$ & $\mathbf{\%}$ \\
\hline Positive & -- & -- & & - & - & - & - & - \\
\hline Negative & 30 & 100.0 & 30 & 100.0 & 30 & 100.0 & 30 & 100.0 \\
\hline
\end{tabular}

Chi-Square Tests

$* *=$ highly significance $* p \leq 0.01$

Table (9): Comparison between studied patients regarding laboratory test findings at different intervals (n=30)

\begin{tabular}{|c|c|c|c|c|c|c|}
\hline \multicolumn{2}{|c|}{ Laboratory test findings } & $\mathbf{N}$ & Mean & Minimum & Maximum & \\
\hline \multirow{4}{*}{$\begin{array}{l}\text { Prothrombin } \\
\text { time }\end{array}$} & Preoperative & 30 & $13.30 \pm .424$ & 12.7 & 14.00 & \multirow[t]{4}{*}{.001} \\
\hline & $1^{\text {st }}$ day postoperative & 30 & $12.57 \pm .438$ & 12.00 & 14.00 & \\
\hline & After two weeks & 2 & $12.25 \pm .371$ & 12.00 & 12.50 & \\
\hline & Total & 62 & $12.58 \pm .470$ & 12.00 & 14.00 & \\
\hline \multirow{4}{*}{$\begin{array}{l}\text { Prothrombin } \\
\text { Concentration }\end{array}$} & Preoperative & 30 & $99.50 \pm .707$ & 87.00 & 100.00 & \multirow[t]{4}{*}{.060} \\
\hline & first day postoperative & 30 & $94.87 \pm 4.562$ & 85.00 & 100.00 & \\
\hline & After two weeks & 2 & $92.23 \pm 5.262$ & 83.00 & 95.00 & \\
\hline & Total & 62 & $92.83 \pm 3.404$ & 81.10 & 100.00 & \\
\hline \multirow{4}{*}{$\begin{array}{c}\text { International } \\
\text { normalised ratio } \\
\text { (INR) }\end{array}$} & Preoperative & 30 & $1.04 \pm .014$ & 1.01 & 1.05 & \multirow[t]{4}{*}{.748} \\
\hline & first day postoperative & 30 & $1.03 \pm .075$ & 1.02 & 1,03 & \\
\hline & After two weeks & 2 & $1.01 \pm .021$ & 1.00 & 1.01 & \\
\hline & Total & 62 & $1.02 \pm .054$ & 1,6 & 1,40 & \\
\hline
\end{tabular}


Table (1): Percentage distribution of demographic data for the studied patients: Showed that; the mean age of patients was $38.5 \mathrm{r}$ years. The most of them was males $(83.3 \%)$, secondary school education $(56.6 \%)$, employed (43.3\%) and married (83.3\%).

Table (2): Percentage distribution of medical data (present history) among studied patients: showed that the majority of studied patients had tourniquet time from 60 to $120(96.7 \%)$, as well the same percentage had surgical duration from 60 to 120 and all patients had no complications during surgery $(100 \%)$, the most of them $(83.3 \%)$ were overweight. Regarding to length of hospital stay it was found that the mean

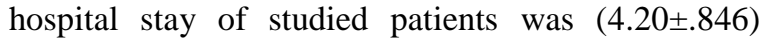
days.

Table (3): Distribution of hospital stay among the studied patients: Showed that; regarding to length of hospital stay it was found that the mean hospital stay

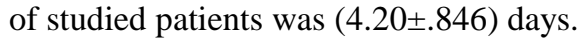

Table (4): Percentage distribution of medical data (past history) among the studied patients: Showed that; $(13.3 \%)$ of patients had previous surgery, $(46.7 \%)$ were smoking, $(6.7 \%)$ had family history of VTE as well the same percentage had history of varicose vein, (3.3\%) had diabetes mellitus, (16.7\%) had hypertension and $(6.7 \%)$ of patients use contraceptive pills.

Table (5): Comparison between Total knowledge score for the studied Patient's pre/post implementing nursing protocol: showed that; there were statistical significant difference regarding total knowledge score for the studied patients pre and post implementing nursing protocol. $\mathrm{P}=0.001$

Table (6): Comparison between studied patients regarding pulmonary embolism manifestation at different intervals $(n=30)$ : Showed that; all patients (pre and postoperatively) were not complained of any signs of PE.

Table (7): Comparison between studied patients regarding deep vein thrombosis manifestation at different intervals $(n=30)$ : showed that; the minority of the patients $(13.3 \%)$ suffered from calf pain and swelling on admission, while after 2 weeks $(6.7 \%)$ of the patients suffered from calf pain and swelling, after 2 months (100\%) of patients did not suffered. Regarding calf tenderness $(6.7 \%)$ of the patients suffered from calf tenderness on admission, while after 2 months $(100 \%)$ of patients did not suffered. As regards discoloration in the leg $(100 \%)$ of the patients did not suffered from discoloration on admission, while in the $1^{\text {st }}$ day postoperative $(3.3 \%)$ of patients suffered from discoloration in the leg, while after 2 months (100\%) of patients did not suffered.

Table (8): Comparison between the studied patients regarding Homan's sign test at different intervals $(n=30)$ : showed that; Homan's sign test (pre and postoperatively) were negative in all patients.

Table (9): Comparison between the studied patients regarding Laboratory test findings at different intervals $(n=30)$ : showed that; preoperatively the studied patients had significantly higher means prthrombin time $(\mathrm{P}=0.001)$.after 2 weeks, they had significantly lower means of prthrombin time $(\mathrm{P}=0.001)$.

\section{Discussion}

Venous thromboembolism is a disorder that includes DVT and PE. A DVT Occurs when a blood clot forms in a deep vein, usually in the lower leg, thigh, or pelvic. PE occurs when a clot breaks loose and travels through the bloodstream to the lungs. The risk of developing VTE is highest after major surgery. Signs and symptoms of DVT include swelling, tenderness, redness, and pain. PE can cause sudden chest pain and shortness of breath. Sometimes VTE occurs without any obvious signs (McCullough et al., 2018).

This study aimed to evaluate the effect of applying educational nursing protocol on minimizing VTE for patients undergoing simultaneously arthroscopic ACLR and HTO.

The present study showed that, the mean age of patients was 38.5 years. This result was in line with Gad\& EL-Sheikh, (2013) who reported that the mean age for study group was $42.03 \pm 13.58$ and for the control group was $41.76 \pm 13.72$ years. The majority of patients were males, secondary school education and employed. This result not agreed with Mohamed et al., (2017) who found that the highest proportions of study participants were females, noneducated and not working. The majority of patients were overweight. This finding is in a line with Murphy et al., (2018) who found that more than $70 \%$ were overweight.

As regard to hospital stay, the results of data collected in this study showed that the mean hospital stay of studied patients was (4.20土.846) days (range 3-6). this result not agreed with Said \& AbdelMoneim, (2017) who found that the mean time for hospital stay was 1.24 days (range: 1-3 days).

It was noticed from the present study that there were statistical significant difference regarding total knowledge score for the studied patients regarding pre and post implementation of nursing protocol. This finding was in congruence with Gad\& EL-Sheikh, (2013) who stated that after intervention there was a significant improved in total knowledge score of the study group as compared to control group.

As regard to the clinical assessment it was noticed that after intervention the patients had an improvement of clinical assessment as evident by 
absence of leg pain, leg swelling, tenderness and discoloration in the leg. This may be due to improvement of knowledge and applying the instruction of preventive measures. This finding of the study was in same line with Gad\& EL-Sheikh, (2013) who carried out a study to evaluate the effect of mechanical measures on prevention of DVT among general surgery patients. This study found that, after intervention the patients of study group had an improvement of clinical assessment as evident by absence of warmth and tenderness in the leg than patients of control group who follow the routine care only.

The present study results demonstrated significantly better prothrombin time related to VTE risk among the studied patients. These laboratory results indicate a better blood clotting profile among the studied patients, with associated lower risk of VTE development.

The present study finding revealed that no patients were developing VTE. The risk for VTE is prevented due to the received instruction to the studied patients about preventive measures including combination of the two prophylactic measures, namely the pharmacologic approach through administration of anticoagulants and the mechanical approach through elastic compression stoking, diet, deep breathing exercises and leg exercises. The anticoagulants act by suppressing the blood hypercoagulability while the elastic stoking act by increasing the venous blood flow velocity and impeding venous stasis in the legs.

This result agreed with Mohamed et al., (2017) who found that $2(6.7 \%)$ patients in the control group had DVT compared with none in the study group. Other study in Japan found that leg exercise is a tool for improving lower extremity venous flow through different modes of exercise in the supine position, and therefore may help prevent lower extremity DVT Shimizu et al., (2017).

This result not agreed with Fuji et al., (2016) who compared the effects of separate and combined mechanical and pharmacological preventive measures to mitigate the development of DVT in orthopedic patients which reported that the incidence of DVT ranged between $6.0 \%$ and $13.0 \%$.

\section{Conclusion}

The study findings showed that implementation of the nursing protocol had statistically significantly positive effect on improving patients' knowledge regarding prevention of VTE and in reducing incidence of VTE.

\section{Recommendations}

- The risk for developing venous thromboembolism among the patients undergoing arthroscopic knee surgery (simultaneously HTO and ACLR) should be assessed by nurses constantly and progressively.

- Replication the study on a larger study sample in different settings is important to generalize the results.

- Nursing protocol should be available in Arthroscopy and sports injury unit and distributed for all patients undergoing simultaneously arthroscopic ACLR and HTO.

\section{References}

1. Afshari, A., Fenger-Eriksen, C., Monreal, M., \& Verhamme, P., (2018): European guidelines on perioperative venous thromboembolism prophylaxis: Mechanical prophylaxis. European Journal of Anaesthesiology (EJA), Vol. (35), No. (2), P.p 112-115.

2. Broadbent, E., Lewin, A., Sylvester, K., Whitfield, B., \& Knowles, D., (2019): Evaluation of Pharmacologic Strategies for Prevention of Venous Thromboembolism in Elective Orthopedic Surgery. Journal of Pharmacy and Pharmacology, Vol. (7), No. (5), P.p 91-97.

3. Calloway, S., Soppe, C., \& Mandelbaum, B., (2018): Clinical Outcomes After Arthroscopic Release of Patellofemoral Arthrofibrosis in Patients With Prior Anterior Cruciate Ligament Reconstruction. Arthroscopy: The Journal of Arthroscopic \& Related Surgery, Vol. (34), No. (5), p. p.1603-1607.

4. Fuji, T., Fujita, S., Kimura, T., (2016): Clinical benefit of graduated compression stockings for prevention of venous thromboembolism after total knee arthroplasty: post hoc analysis of a phase 3 clinical study of edoxaban. Vol. (14), No. (1), P. 13.

5. Gad S., \& EL-Sheikh, A., (2013): Effect of Mechanical Measures on Prevention of Deep Vein Thrombosis among General Surgical Patients. Vol. (81), No. (1), P. p. 1043-1051.

6. Gaskill, Trevor, (2015): The prevalence of symptomatic deep venous thrombosis and pulmonary embolism after anterior cruciate ligament reconstruction. The American journal of sports medicine. Vol. (43), No. (11), P.p 2714-2719.

7. Janssen, R., Reijman, M., Janssen, D., \& Van Mourik, J., (2016): Arterial complications, venous thromboembolism and deep venous thrombosis prophylaxis after anterior cruciate ligament reconstruction: a systematic review. World journal of orthopedics, Vol. (7), No. (9), P. 604. 
8. Jin, C., Song, E., Jin, Q., Lee, N., \& Seon, J., (2018): Outcomes of simultaneous high tibial osteotomy and anterior cruciate ligament reconstruction in anterior cruciate ligament deficient knee with osteoarthritis. BMC musculoskeletal disorders, Vol. (19),No. (1),P. p. 228.

9. Lacut \& Karine, (2011): Mechanical prothylaxis of venous thromboembolism, p.p. 1232-1236.

10. Liew, N., Alemany, G., Angchaisuksiri, P., Bang, S., Choi, G., DE, D., \& Suviraj, J., (2017): Asian venous thromboembolism guidelines: updated recommendations for the prevention of venous thromboembolism. International angiology: a journal of the International Union of Angiology, Vol. (36), No. (1), P.p 1-20.

11. McCullough, M., Kholdani, C., \& Zamanian, R., (2018): Prevention of Deep Vein Thrombosis and Pulmonary Embolism in HighRisk Medical Patients. Clinics in chest medicine, Vol. (39), No. (3), P.p. 483-492.

12. Mohamed, A., Othman, W., El Alphy, B., \& Sheble, A., (2017): Effect of Implementing Nursing Care Guidelines on the Occurrence of Deep Vein Thrombosis among Orthopedic Patients. IOSR Journal of Nursing and Health Science, Vol. (6), No. (3), P. 28.

13. Murphy, P., Vogt, K., Lau, B., Aboagye, J., Parry, N., Streiff, M., \& Haut, E., (2018): Venous thromboembolism prevention in emergency general surgery. Vol. (153), No. (5), P.p. 479-486.

14. Nadim, G., Ekelund, U., Lundberg, J., Brabrand, M., Jensen, H., \& Lassen, A., (2018): Clinical presentation of pulmonary embolism among patients in the emergency department, p. 71

15. Olaf, M., \& Cooney, R., (2017): Deep venous thrombosis. Emergency Medicine Clinics, Vol. (35), No. (4), p. p. 743-770.

16. Ramadan, R., Amr, T.,\& Ashour, E., (2019): Calf muscle pump exercise and preventive measures: as means for prevention of deep vein thrombosis and its manifestations among a postpartum cesarean section. International journal of Nursing Didactics, Vol. (9), No. (4), P.p 49-60.

17. Said, A., \& Abdel-Moneim, H., (2017): The incidence of deep vein thrombosis after knee arthroscopy. The Egyptian Orthopaedic Journal, Vol. (52), No. (4), P. 273.

18. Seung, O., Kyung, W., \& JaeHwi, H., (2018): Opening Wedge High Tibial Osteotomy.Jornal of the korean othopedic Association, Vol .(53),No.(4), p.p. 293-300.

19. Shimizu, Y., Kamada, H., Sakane, M., Aikawa, S., Mutsuzaki, H., Tanaka, K., \& Yamazaki, M., (2017): A novel exercise device for venous thromboembolism prophylaxis improves venous flow in bed versus ankle movement exercises in healthy volunteers. Journal of Orthopedic Surgery, Vol. (25), No. (3), P. p. 1-7.

20. Snyder, M., Sympson, A., Scheuerman, C., Gregg, J., \& Hussain, L., (2017): Efficacy in deep vein thrombosis prevention with extended mechanical compression device therapy and prophylactic aspirin following total knee arthroplasty: a randomized control trial. The Journal of arthroplasty, Vol.(32), No.(5), P.p.1478-1482.

21. Thompson, S., (2012): Simple random sampling. Sampling, P.p. 9-37.

22. Toya, K., Sasano, K., Takasoh, T., Nishimoto, T., Fujimoto, Y., Kusumoto, Y., \& Takahashi, T., (2016): Ankle positions and exercise intervals effect on the blood flow velocity in the common femoral vein during ankle pumping exercises. Journal of physical therapy science, Vol.(28), No.(2), P.p 685-688 .

23. Wheeler H., (1985): Diagnosis of deep vein thrombosis. Review of clinical evaluation and impedance plethysmography. American journal of surgery, Vol. (150), No. (4), P.p. 7-13.

24. Zhu, J., Jiang, H., Marshall, B., \& Tang, X., (2018): Low-Molecular-Weight Heparin for the Prevention of Venous Thromboembolism in Patients Undergoing Knee Arthroscopic Surgery and Anterior Cruciate Ligament Reconstruction: A Meta-analysis of Randomized Controlled Trials. The American journal of sports medicine, Vol. (36), No. (35), P.p. 46-51. 